\title{
Original \\ Article \\ A Single-Center Experience with 73 Patients of Adult Choledochal Cyst: An Indian Perspective
}

\author{
Saket Kumar, Abhijit Chandra, Nikhil Chopra, Rahul, \\ Vishal Gupta, Pradeep Joshi, Vivek Gupta
}

Department of Surgical Gastroenterology,

King George’s Medical University,

Lucknow, Uttar Pradesh, India.

Corresponding Author:

Prof. Abhijit Chandra

Email:abhijitchandra@hotmail.com
ABSTRACT

Background: Aim of the study was to analyze the clinicopathological profile and long-term operative outcomes of patients with choledochal cysts (CDC) undergoing cyst excision.

Methods: Clinical data of 73 adult CDC patients managed at a single tertiary care center between January 2010 and December 2016 were retrospectively analyzed. Patients who had undergone complete cyst excision and with a minimum follow-up of 12 months were included for long-term outcome analysis.

Results: The male female ratio was approximately 1:3 and the median age was 35 years (range, 12-65 years). Type I CDC was the most common cyst type in this series $(n=49 / 73,67.1 \%)$. Abdominal pain was the commonest presenting symptom followed by jaundice, fever and palpable lump. Coexisting gallbladder carcinoma was encountered in 4/73 (5.48\%) patients while two patients had secondary biliary cirrhosis with portal hypertension. Complete cyst excision was performed in 65 out of 73(89.0\%) patients. Patients undergoing complete cyst excision were followed-up for a median duration of 29.5 months (range, 12-70 months). One case of hepaticojejunostomy stricture and two cases of post-operative incisional hernia were reported. No new case of cholangiocarcinoma was reported in any of our patients.

Conclusion: Adulthood CDC are associated with an increased incidence of complications like recurrent cholangitis, pancreatitis and cyst perforation. The lesser association of biliary tract malignancy in Indian population may possibly be linked to a lower incidence of abnormal pancreaticobiliary duct junction. Complete cyst excision with hepaticojejunostomy remains the standard treatment both to relieve the symptoms and to minimize the risk of malignancy.

KEYWORDS: Adult, Choledochal Cyst, Cholangitis, Cholangiocarcinoma, Hepaticojejunostomy. 


\section{Introduction}

Choledochal cysts (CDC) are rare congenital disorder characterized by abnormal dilation of the bile ducts. Majority of these patients are diagnosed during the first decade of life, however, presentation in late adulthood is not uncommon. ${ }^{1}$ The estimated incidence ranges from 1 in 50,000 to 1 in 200,000 live births in Western countries but is much more frequent in Asian population. ${ }^{2,3}$ Magnetic Resonance Cholangiography (MRCP) is considered the investigation of choice to diagnose and classify the biliary cysts. ${ }^{3,4}$ The classification system based on the extent, site and shape of the cyst was originally proposed by Alonso-Lej and later modified by Todani et $\mathrm{al}^{5,6}$. The clinicopathological profile of adult CDC patients differs from childhood patients. ${ }^{7}$

This retrospective study was performed with an aim to analyze the demographic and clinicopathological profile of CDC patients among Indian adults and their outcomes following surgical excision of the cyst. In this study we have analyzed whether adult CDC in Indian population is any different from other high incidence population groups.

\section{Materials And Methods}

The study was conducted at a tertiary level teaching hospital of North India. Medical records of all adult patients ( $>12$ years age) with CDC who were managed in our Department between January 2010 and December 2016 were reviewed retrospectively. The diagnosis of CDC in these patients was based on ultrasound, cholangiography (ERC/MRCP) and/or computed tomography findings. Factors studied included demographic data, presenting symptoms, investigation profile, associated illness, surgical procedures, perioperative complications and outcomes. Radiological reports and operative findings were reviewed to classify the CDC according to modified Todani system. History of any prior intervention was recorded. Postoperative complications were classified according to Clavien-Dindo classification. ${ }^{8}$ Following surgery, follow-up was done at 2 and 6 weeks, then 3-monthly for the first year, biannually for the second year, and annually thereafter. In each visit, patients were examined clinically and were also interviewed for disease-specific symptoms. Biochemical surveillance by liver function tests and abdominal ultrasound were done at 6 monthly intervals. Patients with a minimum followup of 12 months following complete cyst excision were selected for long-term outcome analysis. Patients with co-existing malignancy $(n=4)$ were excluded from the analysis.

Laparoscopic surgery was done using 4-5 ports. Gall bladder was first dissected from liver bed. The cyst was then dissected and looped using umbilical tape. After complete cyst mobilization, the lower end of the cyst was divided at the tapering point using linear stapling device. The upper end was divided at the confluence in patients of Type IVA cyst and at the taper point in Type I cyst Specimen was extracted out using one of the ports. End to side hepaticojejunostomy was done in a single layer using absorbable monofilament suture. In laparoscopicassisted procedure, reconstruction was done via $8 \mathrm{~cm}$ right subcostal incision. Gastrointestinal continuity was restored with a side-to-side stapled jejunojejunostomy. A drain was placed near hepaticojejunostomy anastomosis at the completion of the surgery.

\section{Results}

Seventy-three patients of adult CDC were identified with a median age of 35 years (range, 12-65 years) (Table 1). Most commonly affected age group was between 12 and 20 years age group (Figure 1). Four patients had coexistent gall bladder carcinoma (GBC). Median age was $42.5 \mathrm{yr}$ (31-50 yr).

\section{Symptomatology}

Abdominal pain was the most common presenting symptom $(94.5 \%, \mathrm{n}=69 / 73)$ followed by jaundice $(n=24 / 73 ; 32.9 \%)$ and fever $(n=17 / 73 ; n=23.3 \%)$. Median bilirubin level of patients presenting with jaundice was $3.94 \mathrm{mg} / \mathrm{dl}$ (range, $1.8-18.2 \mathrm{mg} / \mathrm{dl}$ ). The classical triad of pain, jaundice and lump was not seen in any of our patients (Figure 2). History of pancreatitis and cholangitis was present in $8.2 \%(n=6 / 73)$ and $19.2 \%(n=14 / 73)$ patients respectively. Abdominal lump, cyst perforation and gastric outlet obstruction (GOO) were only rarely encountered 
(Table 1). Four out of six patients with abdominal lump had complains of abdominal swelling, while in 2 patients lump was discovered on clinical examination. All patients with coexistent GBC had pain abdomen at the presentation and only one had palpable abdominal lump (Table 1). We have reported one case each of cyst perforation and GOO in our previously published series on unusual presentation of CDC. ${ }^{9}$ The GOO in both of our patients was due to external compression of duodenum by a large CDC.

\section{Associated Pathologies}

Ten out of seventy-three (13.7\%) patients had associated pathologies (Table 1). Four patients with co-existing gallbladder carcinoma (GBC) underwent extended cholecystectomy/modified right hepatectomy, lymph node clearance and CDC excision.

\section{Characteristics of $C D C$}

CDC was classified as per modified Todani's classification based on radiological and intra-operative findings (Table 1). Median diameter of the cyst was $2.2 \mathrm{~cm}$ ranging from 1.1 to $40 \mathrm{~cm}$. Cystolithiasis was associated in 49 out of $73(67.1 \%$ ) patients, while intrahepatic biliary radical dilatation (IHBRD) was noted in $50.6 \%(\mathrm{n}=37 / 73)$ of patients. On review of available cholangiography images and reports, anomalous pancreato-biliary ductal

Table 1: Demographic and clinico-pathological profile of adult choledochal cysts $(n=73)$.

\begin{tabular}{|c|c|c|}
\hline S. No & Demographic variable & Result \\
\hline 1 & Age & Median: 35 (range, 12-65) \\
\hline 2 & Sex & $\mathrm{M}: \mathrm{F}=19: 54$ \\
\hline 3 & $\begin{array}{l}\text { Symptomatology } \\
\text { Pain } \\
\text { Jaundice } \\
\text { Fever } \\
\text { Recurrent Cholangitis } \\
\text { Lump } \\
\text { Weight loss } \\
\text { Pancreatitis } \\
\text { Gastric outlet obstruction } \\
\text { Perforation of the cyst }\end{array}$ & $\begin{array}{l}69(94.5 \%) \\
24(32.9 \%) \\
17(23.3 \%) \\
14(19.2 \%) \\
6(8.2 \%) \\
4(5.5 \%) \\
6(8.2 \%) \\
2(2.7 \%) \\
2(2.7 \%)\end{array}$ \\
\hline 4 & $\begin{array}{l}\text { Prior interventions } \\
\text { Cholecystectomy } \\
\text { Cholecystectomy with CBD exploration } \\
\text { ERC stenting }\end{array}$ & $\begin{array}{l}31(42.4 \%) \\
13 \\
7 \\
13\end{array}$ \\
\hline 5 & $\begin{array}{l}\text { Associated pathologies } \\
\text { Carcinoma Gallbladder } \\
\text { Ulcerative colitis } \\
\text { Situs inversus totalis } \\
\text { Annular Pancreas } \\
\text { Secondary biliary cirrhosis } \\
\text { Chronic pancreatitis }\end{array}$ & $\begin{array}{l}10(13.7 \%) \\
4 \\
1 \\
1 \\
1 \\
2 \\
1\end{array}$ \\
\hline 6 & $\begin{array}{l}\text { Type of CDC(as per Todani Classification) } \\
\text { I } \\
\text { II } \\
\text { III } \\
\text { IV A } \\
\text { IV B } \\
\text { V }\end{array}$ & $\begin{array}{l}49(67.1 \%) \\
1(1.3 \%) \\
0 \\
19(26.0 \%) \\
4(5.4 \%) \\
0\end{array}$ \\
\hline
\end{tabular}

ERC: Endoscopic Retrograde Cholangiography; CBD: Common Bile Duct; CDC: Choledochal cyst. 


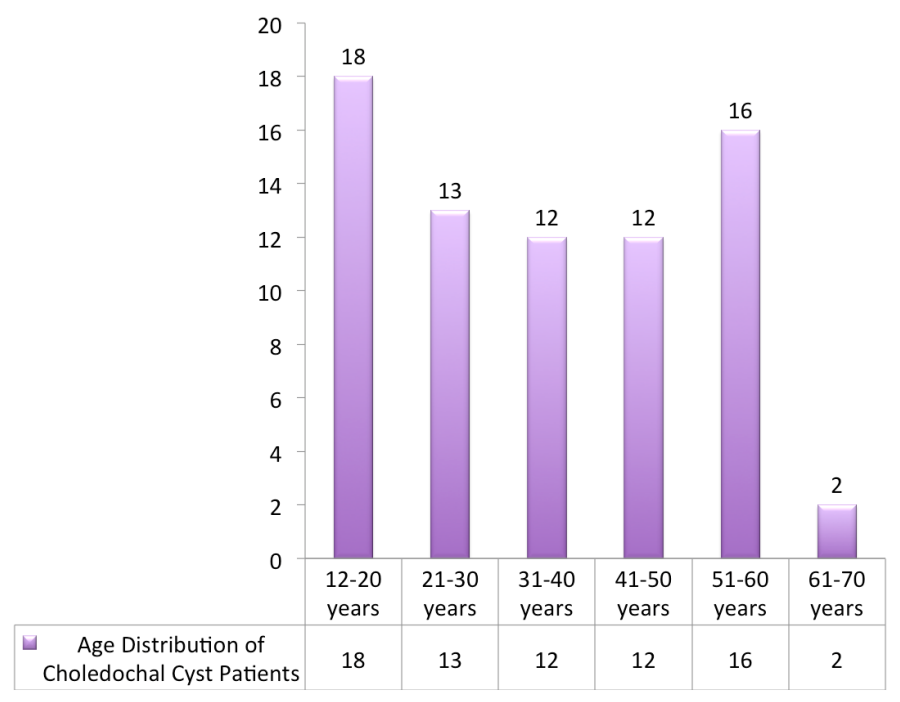

Figure 1: Figure showing the age distribution of CDC patients.

junction (APBDJ) was found to be associated in 12 out of $60(20 \%)$ patients.

\section{Surgical Procedure}

Complete cyst excision was performed in 65 out of $73(89.0 \%)$ patients. Out of these, four patients underwent complete CDC excision along with extended cholecystectomy/ modified right hepatectomy for coexisting GBC. Open surgical resection was performed in $61(88.4 \%)$ patients. Lately, laparoscopic approach has been applied in selected patients with CDC (medically fit young patients, no recent cholangitis/pancreatitis and no prior intervention). Three patients underwent partial cyst excision (Lilly's procedure) because of presence of dense peri-cystic adhesions. In five patients only T-tube drainage could be done at the initial exploration, as cyst resection was deemed too hazardous. Out of these, one patient underwent Lilly's procedure at a later dateand is doing well in the follow-up (Table 2). Another patient never reported to us in the follow-up and could not be traced either. Rest of the patients too didn't comply with the advice of timely follow-up and landed up in serious complications. Two patients developed fatal cholangitis and one reported after 4 years with complication of retained T-tube. The later had developed choledochoduodeno-colic fistula with partial migration of T-tube in

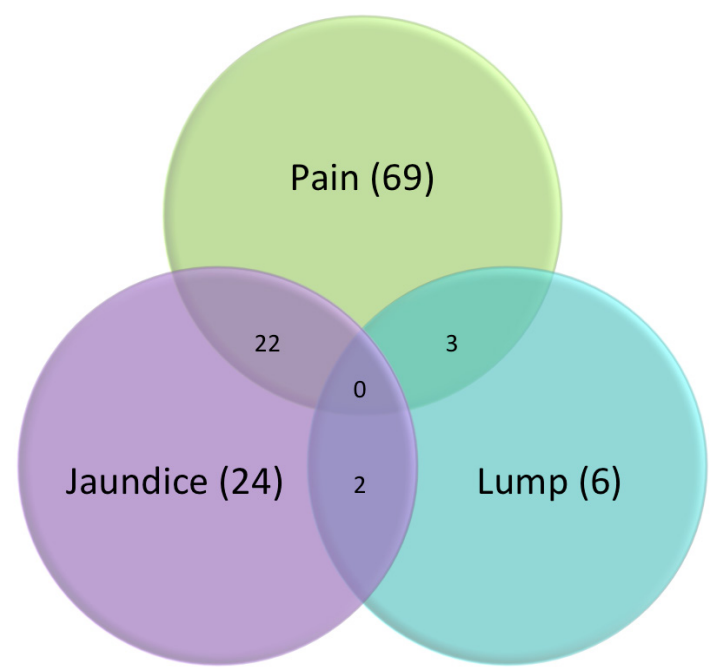

Figure 2: Figure showing the distribution of the presenting symptoms of choledochal cyst patients.

the ascending colon. She required dismantling of fistula with colonic resection and repair of duodenal rent. The choledochal cyst couldn't be excised due to presence of dense adhesions in hepatoduodenal region.

\section{Perioperative Outcome following CDC excision}

Mean operative time, blood loss, hospital stay and early complications following cyst excision and hepaticojejunostomy have been shown in table 3 and 4 . Eight patients underwent laparoscopic CDC excision. All these patients had uneventful, complication-free postoperative course (Table 4 and 5). Postoperative morbidity was graded as per Clavien-Dindo classification (Table 3). Six patients had ISGLS grade-A biliary leak and other two had ISGPF grade-B postoperative pancreatic fistula. ${ }^{10,11}$ Two operative mortalities occurred on post-operative day 3 and 9 , due to severe sepsis leading to multi-organ failure in both patients.

\section{Histopathology}

All operative specimens were subjected to histopathological analysis. Histopathological findings were consistent with CDC. None of the patients had coexisting dysplasia or occult malignancy. Out of 4 patientswith coexistent GBC, 3 patients had stage III disease and one patient had stage II disease as per AJCC 7th edition. ${ }^{12}$ 
Table 2: Details of the surgical procedure for choledochal cysts and post-operative outcomes.

\begin{tabular}{l|l|l} 
S. No & Variable & Number (Percent) \\
\hline 1 & Surgical Procedure Done & \\
& Complete cyst excision + RYHJ & $60(82.2 \%)$ \\
& CDC excision with extended cholecystectomy + RYHJ & $2(2.7 \%)$ \\
& CDC excision with extended cholecystectomy with segmental colonic resection + RYHJ & $1(1.4 \%)$ \\
& CDC excision with extended right hepatectomy + RYHJ & $1(1.4 \%)$ \\
& CDC excision with Frey's procedure & $1(1.4 \%)$ \\
& Lilly's procedure + RYHJ & $3(4.1 \%)$ \\
& T-tube drainage followed by interval Lilly's procedure & $1(1.4 \%)$ \\
& T-tube drainage only & $4(5.48 \%)$ \\
\hline 2 & Cyst excision with RYHJ: Surgical approach & N=69 \\
& Open & $61(88.41 \%)$ \\
& Laparoscopic & $4(5.8 \%)$ \\
& Laparoscopic assisted & $4(5.8 \%)$ \\
\hline
\end{tabular}

CDC: Choledochal cyst; RYHJ: Roux-en-Y Hepaticojejunostomy.

Table 3: Early post-operative outcomes following CDC excision and RYHJ $(n=56) *$

\begin{tabular}{l|l|l} 
S. No & Variable & Number (Percent) \\
\hline 1 & Postoperative morbidity & $18(30.0 \%)$ \\
& Clavien-Dindo Grade I & $8(13.33 \%)$ \\
& Clavien-Dindo Grade II & $0(0.0 \%)$ \\
& Clavien-Dindo Grade III & $1(1.67 \%)$ \\
& Clavien-Dindo Grade IV & $2(3.33 \%)$ \\
\hline 2 & Clavien-Dindo Grade V & \\
& Complications & 12 \\
& Surgical site infection & 6 \\
& Bile leak (ISGLS Grade A) & 1 \\
& Bile leak (ISGLS Grade C) & 4 \\
& Pyrexia & 2 \\
& Pancreatic fistula (ISGPF Grade B) & 2 \\
& Retching/ vomiting & 1 \\
\hline 3 & Psychosis & 2 \\
\hline & Death & 8 days (range, 5-22) \\
& Median postoperative hospital stay (day) & 8.5 days (range, 5-22) \\
& Open procedure & 6.5 days (range, 6-15) \\
\hline
\end{tabular}

RYHJ: Roux-en-Y Hepaticojejunostomy; ISGLS: International Study Group of Liver Surgery; ISGPF: International Study Group of Pancreatic Fistula.

*Patients undergoing complete CDC excision and RYHJ were included. Patients undergoing pancreaticojejunostomy and hepatectomy for carcinoma gallbladder were excluded. Three cases with combined extended cholecystectomy had median postoperative hospital stay of 7 days, and another case of modified right hepatectomy had a post-operative stay of 11 days. 
Table 4: Open versus laparoscopic approach of cyst excision: early outcomes.

\begin{tabular}{l|l|l} 
Parameters & Open approach $(\mathbf{n}=\mathbf{5 0}) *$ & Laparoscopic Approach $(\mathbf{n}=\mathbf{6})^{\#}$ \\
\hline Mean operative time (minutes) & 170 (range, $150-340)$ & 300 (range, 270- 360) \\
\hline Mean blood loss (ml) & 180 (range, $100-220)$ & 150 (range, 120- 250) \\
\hline Median hospital stay (days) & $8.5(5-22$ days) & $6.5(6-12$ days $)$ \\
\hline Bile leak & $5(9.61 \%)$ & $2(25 \%)$ \\
\hline Surgical site infection & $12(23.07 \%)$ & 0 \\
\hline
\end{tabular}

*Included cases of complete cyst excision with hepaticojejunostomy. Four cases with co-existing gallbladder malignancy in whom hepatectomy was performed were also excluded.

"Included cases of complete laparoscopic and laparoscopic-assisted complete cyst excision and hepaticojejunostomy.

Table 5: Univariate analysis of factors predicting early post-operative complications in 65 patients who underwent cyst excision (complete/ partial) with hepaticojejunostomy. Four cases with co-existing gallbladder malignancy in whom hepatectomy was performed were excluded.

\begin{tabular}{|c|c|c|c|}
\hline PARAMETER & SSI & BILE LEAK & POPF \\
\hline $\begin{array}{l}\text { AGE } \\
\qquad 40(\mathrm{~N}=40) \\
\quad>40(\mathrm{~N}=25) \\
\text { P value }\end{array}$ & $\begin{array}{c}8 \\
6 \\
0.9\end{array}$ & $\begin{array}{c}6 \\
3 \\
1.0\end{array}$ & $\begin{array}{c}2 \\
0 \\
0.69\end{array}$ \\
\hline $\begin{array}{l}\text { PRIOR INTERVENTION } \\
\text { YES }(\mathrm{N}=25) \\
\text { NO }(\mathrm{N}=40) \\
\text { P value }\end{array}$ & $\begin{array}{c}9 \\
5 \\
0.053\end{array}$ & $\begin{array}{c}1 \\
8 \\
0.15\end{array}$ & $\begin{array}{c}1 \\
1 \\
0.69\end{array}$ \\
\hline $\begin{array}{l}\text { RECURRENT CHOLANGITIS } \\
\text { YES }(\mathrm{N}=12) \\
\text { NO }(\mathrm{N}=53) \\
\text { P value }\end{array}$ & $\begin{array}{r}5 \\
9 \\
0.14 \\
\end{array}$ & $\begin{array}{c}2 \\
7 \\
0.89 \\
\end{array}$ & $\begin{array}{c}0 \\
2 \\
0.81 \\
\end{array}$ \\
\hline $\begin{array}{l}\text { APPROACH } \\
\text { LAPAROSCOPIC (N=8) } \\
\text { OPEN (N=57) } \\
\text { P value }\end{array}$ & $\begin{array}{c}0 \\
14 \\
0.26\end{array}$ & $\begin{array}{c}2 \\
7 \\
0.67\end{array}$ & $\begin{array}{c}0 \\
2 \\
0.58\end{array}$ \\
\hline
\end{tabular}

SSI: Surgical site infection.

\section{Follow Up}

Out of 73, 67 patients who underwent CDC excision were followed up (4 patients had T-tube drainage alone and 2 in-hospital mortality). Follow-up data was available for 51 patients. One patient expired after 3 month of surgery due to unrelated reason. Three patients with GBC were excluded (one expired 3 months after surgery). Thirteen patients had a follow-up less than 12 months (Figure 3). Median follow-up was 29.5 month (range, 12-70 month). Out of remaining 34 patients, one patient developed hepaticojejunostomy stricture that was refractory to percutaneous trans-hepatic dilatations and required revision hepaticojejunostomy. Two patients developed incisional hernia in the follow-up; both underwent open mesh hernioplasty and are doing well after that.

Four patients presented with coexistent GBC. Follow-up data was available for 3 patients. One patient expired after 4 month of surgery due to disease recurrence. Two patients are alive and disease-free at a follow-up of 6 and 15 months. 


\section{Discussion}

CDCs are rare congenital anomaliesfirst described by German anatomist Abraham Vater in the year $1723 .{ }^{13}$ CDCs have a reported incidence of 1 in 100 000-150 000 live births in the western population. ${ }^{1}$ However, the occurrence is much higher in Asian population with an incidence of 1 in $1000 .{ }^{14}$ Majority of the CDC cases are diagnosed during infancy, whereas approximately 15$20 \%$ remain undetected till adulthood. ${ }^{1}$ In our hospital, majority of the neonatal and pediatric CDC patients are managed in the department of pediatric surgery and adult patients are referred to us. To avoid the referral bias, we limited our study to the analysis of adult patients only. In the current study, 73 adult CDC patients were managed in a single department over a period of 7 years. The CDC occurs predominantly in females with a reported ratio of $3: 1$ to $4: 1$, although the reason for this gender predisposition is unclear. ${ }^{1,14}$ In the present study, we observed a female: male ratio of about $3: 1$, which is consistent with findings in available literature.

The clinical presentation of CDC in adults is often vague and non-specific. The classical triad of jaundice, right subcostal lump and abdominal pain is seen in less than $20 \%$ of adult CDC patients at presentation. ${ }^{14}$ Several studies have reported higher association of cirrhosis, pancreatitis, choledocholithiasis and cholangitis in adult CDC as compared to pediatric patients. ${ }^{10}$ In our series, the most common presenting symptom was of pain abdomen, which was reported in about $94.5 \%(n=69 / 73)$ of patients. The classical triad of abdominal pain, lump and jaundice was not manifested in any of our patients. However, 27 out of 73 patients presented with two out of these three classical symptoms (Figure 2). In this series, $8.2 \%(\mathrm{n}=6 / 73)$ of patients had history of pancreatitis and $19.2 \%(n=14 / 73)$ patients had suffered recurrent cholangitis in the past. Two patients in the study group were discovered to have secondary biliary cirrhosis and portal hypertension intraoperatively. Cyst excision was not possible in these patients due to presence of pericystic collaterals and dense adhesions.

Cystolithiasis and cholelithiasis were associated with $67.1 \%(n=49 / 73)$ of patients in our study. This corresponds to the findings of other studies in which

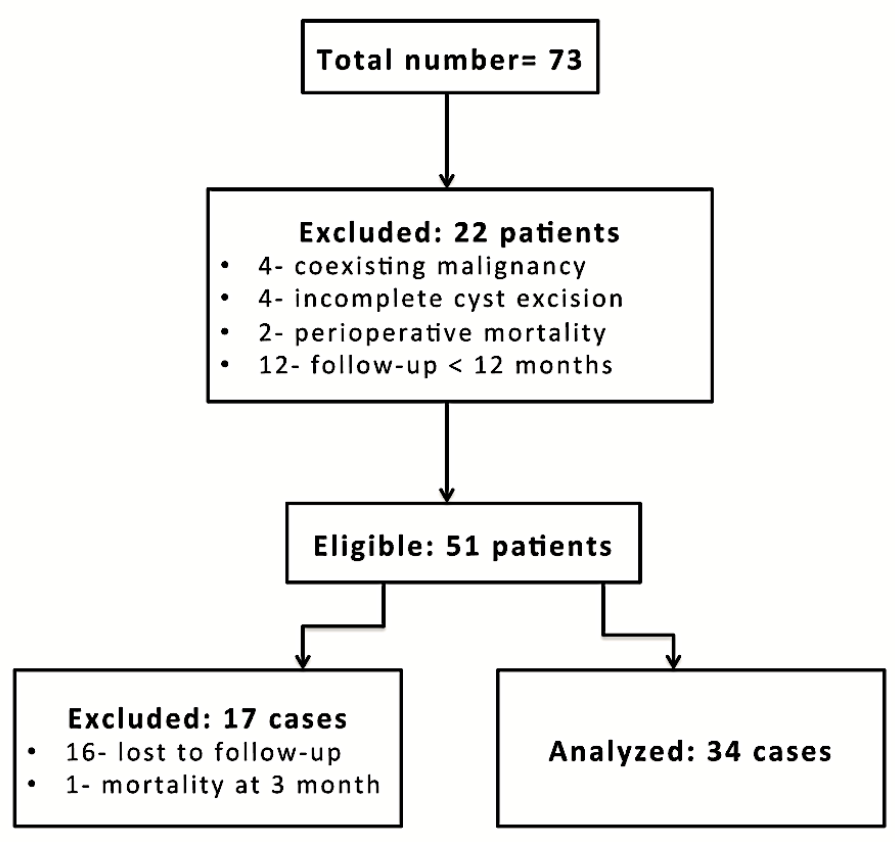

Figure 3: Inclusion and exclusion criteria used to select patients for outcome analysis in this retrospective study.

adult CDC patients were shown to be associated with cholelithiasis or cystolithiasis in $45-70 \%$ of patients. ${ }^{1}$ Presence of stone superimposed with underlying symptoms of CDC (commonly pain or jaundice) may cause significant diagnostic dilemma, especially when patients are initially evaluated at smaller center lacking adequate expertise and facilities. Misdiagnosis often results in inappropriate surgical interventions, rendering definitive surgery difficult. ${ }^{1}$ In our study, $27.4 \%$ ( $n=20 / 73$ ) of patientshad history of prior surgical interventions in the form of cholecystectomy or common bile duct exploration (Table 1). When symptoms persisted even after intervention, these patients were referred to our center where on work-up correct diagnosis was revealed.

Etiological basis of CDC is poorly understood. The most widely accepted theory is the presence of an APBDJ that predisposes the reflux of pancreatic juice into the bile duct, causing weakening of the biliary tree and eventually resulting in its cystic dilation. ${ }^{3}$ Studies from Southeast Asian region haveconsistently reporteda high incidence of APBDJ in CDCcases. ${ }^{16-23}$ (Table 6), though larger series from other parts of World have shown a weaker link. ${ }^{13-15}$ The incidence of APBDJ has been found to be low in major Indian series as well. ${ }^{15,24-29}$ In the 
present study, APBDJ was present $20 \%$ of patients, which is consistent with previous findings in Indian patients (Table 7). The APBDJ is a known risk factor for biliary tract malignancy.The chronic pancreaticobiliary reflux incites inflammation in the gallbladder and bile duct mucosa, thus leading to dysplasia and malignant changes. ${ }^{33-36}$ Worldwide, the incidence and type of malignancy associated with $\mathrm{CDC}$ varies widely. Cholangio carcinoma is the most common malignancy associated with $\mathrm{CDC}$ and up to $35 \%$ occurrence has been reported in Japanese and Korean studies. ${ }^{15,37,38}$ In our series, only $20 \%(n=12 / 60)$ patients had APBDJ and also the association with biliary malignancy was quite low. This lends credence to hypothesis of causal relationship between APBDJ and biliary tract carcinomas. In our study, all 4 patients with coexisting malignancyhad carcinoma of the gallbladder. The predilection fordeveloping of GBC in Indian patients remains unknown, though environmental and ethnic factors may have some role to play. ${ }^{39}$

The goals of treatment of CDC are to relieve the symptoms, abolish pancreatic enzyme reflux, restore normal bile flow and minimize the risk of malignancy. Complete excision of the extrahepatic bile duct along with gallbladder achieves these goals and is considered

Table 6: Major Southeast Asian series on Choledochal cyst and Abnormal Pancreaticobiliary Duct Junction Association.

\begin{tabular}{l|l|l|l|l|l|l}
\hline Author & Year & Country & Number & APBDJ & Malignancy & Site of malignancy \\
\hline Yamaguchi $^{16}$ & 1980 & Japan & $\begin{array}{l}\text { Total } 1433 \\
(534 \text { adults })\end{array}$ & Not reported & $11.2 \%(60)$ & $\begin{array}{l}\text { EHBD- 76.6\% (46) } \\
\text { GB- 21.6\% }(13)\end{array}$ \\
\hline Komi et al. ${ }^{17}$ & 1984 & Japan & 645 & $90.2 \%$ & $8.4 \%(54)$ & $\begin{array}{l}\text { EHBD- 55.5\% (30) } \\
\text { GB- 29.6\% (16) }\end{array}$ \\
\hline Song et al. ${ }^{18}$ & 1999 & S Korea & 52 & $84.6 \%$ & $17.3 \%(9)$ & $\begin{array}{l}\text { EHBD- 44.4\% (4) } \\
\text { GB- 33.3\% (3) }\end{array}$ \\
\hline Liu et al. ${ }^{19}$ & 2002 & Hong Kong & 30 & N/R & $30 \%(9)$ & $\begin{array}{l}\text { EHBD-77.7\% (7) } \\
\text { GB- 22.2\% }(2)\end{array}$ \\
\hline Zheng et al. ${ }^{20}$ & 2004 & China & 72 & $1.4 \%$ & $5.5 \%(4)$ & EHBD- 100\% (4) \\
\hline Liu et al. ${ }^{21}$ & 2007 & China & 122 & $39.34 \%$ & $13.11 \%(16)$ & EHBD- 100\% (16) \\
\hline Huang et al. ${ }^{22}$ & 2010 & Taiwan & 59 & $59.6 \%$ & $21.2 \%(11)$ & $\begin{array}{l}\text { EHBD- 72.7\% (8) } \\
\text { GB- 9.0\% }(1)\end{array}$ \\
\hline Lee et al. ${ }^{23}$ & 2011 & S Korea & 808 & $71.4 \%$ & $9.9 \%(80)$ & $\begin{array}{l}\text { EHBD- 48.8\% (39) } \\
\text { GB- 43.8\% (35) }\end{array}$ \\
\hline
\end{tabular}

APBDJ: Abnormal Pancreatico-Biliary Duct Junction; EHBD: Extrahepatic Bile Duct; GB: Gall Bladder.

Table 7: Findings of major Indian series on choledochal cyst and abnormal pancreaticobiliary duct junction association.

\begin{tabular}{|c|c|c|c|c|c|}
\hline Author & Year & Number & APBDJ & Malignancy & Site of malignancy \\
\hline Chaudhary et al. ${ }^{2}$ & 1996 & 27 & $29.6 \%$ & $3.7 \%(1)$ & EHBD-100\% (1) \\
\hline Jesudason et al. ${ }^{15}$ & 2006 & 57 & $14 \%$ & 0 & - \\
\hline Palanivelu et al..$^{25}$ & 2008 & 35 (all age group) & $40 \%$ & $8.5 \%(3)$ & EHBD-100\% (1) \\
\hline Dhupar et al. ${ }^{26}$ & 2009 & 14 & $\mathrm{~N} / \mathrm{R}$ & 0 & - \\
\hline Saluja et al. ${ }^{27}$ & 2012 & 132 (120 adults) & $24 \%$ & $3.3 \%(4)$ & GB- $100 \%(4)$ \\
\hline Dandpat et al. ${ }^{28}$ & 2014 & 30 & $\mathrm{~N} / \mathrm{R}$ & $3.3 \%(1)$ & EHBD-100\% (1) \\
\hline Patil et al. ${ }^{29}$ & 2015 & 56 (16 adults) & $\mathrm{N} / \mathrm{R}$ & 0 & - \\
\hline Current study & 2017 & 73 & $25 \%$ & $5.5 \%(4)$ & GB- $100 \%(4)$ \\
\hline
\end{tabular}

APBDJ: Abnormal Pancreatico-Biliary Duct Junction; GB: Gall Bladder; EHBD: Extrahepatic Bile Duct; N/R: Not Reported. 
the optimal treatment for type I and II cyst. ${ }^{40,41}$ For type III cysts, endoscopic papillotomy is considered adequate, as the risk of development of malignancy is low. Type IV $\mathrm{CDC}$ is treated by excision of the extrahepatic component of the cyst. Liver resection is reserved for patients with intrahepatic stones, stricture or recurrent cholangitis/ abscess. ${ }^{13,40}$ In few patients, presence of dense pericystic adhesions renders complete cyst excision difficult and hazardous. In such patients, a part of the posterior cyst wall can be safely left behind after obliteration of mucosal lining (Lilly's procedure). ${ }^{13}$ In our series, 65 out of 73 patients underwent complete excision of the cyst with Roux en Y hepaticojejunostomy. Lilly's procedure (partial cyst excision) was done in 4 patients, one of whom had trial resection and T-tube drainage 6 weeks earlier. In 4 patients, only T-tube drainage could be done because of presence of dense adhesions, pericholedochal collaterals or portal hypertension. Liver resection for intrahepatic cyst was not performed in any of our patients.

Recently, CDC excision has been done laparoscopically with encouraging initial results. It provides the usual benefits of laparoscopic surgery like minimal scar, reduced pain and faster recovery with equivalent complication rates. ${ }^{13,42}$ In the present series, 4 patients underwent laparoscopic-assisted CDC excision (laparoscopic cyst excision followed by open reconstruction) while rest 4 underwent total laparoscopic procedure (complete cyst excision and reconstruction laparoscopically). The operative time was longer as compared to open surgery. This reflects longer learning curve related to this complex surgery and with growing experience, the operative time is expected to shorten. Blood loss and post-operative hospital stay were less as compared to open group. No significant difference in the complication rate was recorded in patients undergoing laparoscopic resection as compared to open resection (Table 5). The improved perioperative outcomes may be partly attributed fact that only fit and easy patients were selected for laparoscopic surgery. Although the number of patients undergoing laparoscopic surgery was small and patients were highly selected, it supports the feasibility and safety of minimally invasive approach in the management of CDC.

$$
\text { CDC excision with Roux-en-Y }
$$

hepaticojejunostomy was tolerated well by the patients and had minor procedure-related complications. Surgical site infection and bile leak were most common early complications that were managed conservatively. On further analysis, the incidence of surgical site infection was found to be significantly higher in patients with history of previous endoscopic or surgical interventions. Although the exact reason for this finding is not known, but it may be attributed to certain factors such as- the presence of bactibilia in patients with history of endoscopic interventions and need for extensive dissection and adhesiolysis in patients with prior surgical interventions, that might have increased the incidence of infective complication (Table 5). Two patients had post-operative pancreatic fistula, which gradually healed without need of any intervention. Two patients died on postoperative day 2 and 9 due to severe sepsis leading to multiorgan failure.

In the present study, at a median follow-up of 29.5 months (range, 12-70 month), no patient developed malignancy of the biliary tract. The incidence of malignancy after complete cyst excision has been found to be virtually non-existent in other Indian series as well. ${ }^{15,27}$ However, long-term risk of subsequent biliary tract malignancy has been reported higher in Korean and Japanese population. ${ }^{16-23}$ The potential explanation of this finding could be described by a shorterduration of followup, lower incidence of APBDJ and complete cystexcision rather than drainage procedure done in majority of our patients. The overall incidence of long-term complications following CDC excision was low in our study. One patient presented with anastomotic stricture in the follow-up. Revision surgery was done after failed initial percutaneous dilatation therapy. In studies done by Singham et al. and Lipsett et al., the rate of anastomotic stricture was $12 \%$ and $2.3 \%$ respectively. ${ }^{2,40}$ They have emphasized the importance of tension free, adequate sizedbilio-enteric anastomosis to avoid anastomotic stricture formation in the long-term. No patient in our study presented with the symptoms of cholangitis in the postoperative period. The most common cause of recurrent cholangitis the followup is either development of anastomotic stricture or due to intrahepatic stones especially seen in patients of type IV-A CDC. ${ }^{2,30}$ Lower incidence of anastomotic stricture and lesser proportion of type IV-A patients in our study 
could have resulted in lower rates of cholangitis in the long-term.

\section{Conclusion}

Adult CDC is not an uncommon entity in Indian population. Complete CDC excision remains the most appropriate surgical procedure. Low frequency of APBDJ, high incidence of GBC and lack of development of malignancy in the follow-up make it different from other series in literature.

\section{References}

1. Soares KC, Arnaoutakis DJ, Kamel I, Rastegar N, Anders $\mathrm{R}$, Maithel S, et al. Choledochal cysts: Presentation, Clinical differentiation and management. J Am Coll Surg. 2014; 219 (6): 1167-1180.

2. Singham J, Schaeffer D, Yoshida E Scudamore C. Choledochal cysts: Analysis of disease pattern and optimal treatment in adult and paediatric patients. HPB 2007; 9:383-387.

3. Soreide K, Korner H, Havnen J Soreide JA. Bile duct cysts in adults. Br J Surg. 2004; 91:1538-1548.

4. Irie H, Honda H, Jimi M, Yokohata K, Chijiwa K, Kuroiwa $\mathrm{T}$ et al. Value of MR cholangiopancreaticography in evaluating choledochal cysts. Am J Roentgenol. 1998; 17(1): 1381-1385.

5. Alonso-Lej, Rever W, Pessagno D. Congenital choledochal cysts, with report of 2, and an analysis of 94 cases. Int Surg. 1959; 108: 1-30.

6. Todani T, Watanabe Y, Narusuc M, Tabuchi K, Okajima $\mathrm{K}$. Congenital bile duct cysts: classification, operative procedures, and review of thirty-seven cases including cancer arising from choledochal cyst. Am J Surg. 1977; 134:263-269.

7. Ouaissi M, Kianmanesh R, Ragot E, Belghiti J, Wildhaber B, Nuzzo G et al. French Surgical Association. Congenital bile duct cyst (BDC) is a more indolent disease in children compared to adults, except for Todani type IV-A BDC: results of the European multicenter study of the French Surgical Association. HPB. 2016; 18(6):529-539.

8. Dindo D, Demartines N, Clavien PA. Classification of Surgical complications. A new proposal with evaluation in a cohort of 6336 patients and results of a survey. Ann Surg. 2004; 240(2):205-213.

9. Gupta N, Gupta V, Noushif M, Singh SK, Kumar P, Chandra
A. Unusual presentations of choledochal cyst: case series and review of literature. Indian J Surg. 2015;77(3): 13191322.

10. Brooke-Smith M, Fiqueras J, Ullah S, Rees M, Vauthey JN, Hugh TJ et al. Prospective evaluation of the International Study group for liver surgery definition of bile leak after a liver resection and the role of routine operative drainage: an international multicentre study. HPB (Oxford). 2015 Jan; 17(1):46-51.

11. Bassi C, Dervenis C, Butturini G, Fingerhut A, Yeo C, Izbicki J et al. International Study Group on Pancreatic Fistula Definition. Postoperative pancreatic fistula: an international study group (ISGPF) definition. Surgery 2005 Jul; 138(1); 8-13.

12. Edge SB, Byrd DR, Compton CC, Fritz AG, Greene FL, Trotti A. 3rd, editor, AJCC Cancer Staging Manual. 7. New York: Springer; 2010.

13. Machado NO, Chopra PJ, Al-Zadjali A, Younas S. Choledochal cyst in adults: Etiopathogenesis, presentation, management and outcome - Case series and Review. Gastroenterol Res and Pract. 2015; 2015: 602591.

14. Park SW, Koh H, Oh JT, Han SJ, Kim S. Relationship between anomalous pancreaticobiliary ductal union and pathologic inflammation of bile duct in choledochal cyst. PediatrGastroenterolHepatolNutr. 2014; 17(3): 170-177.

15. Jesudason BSR, Jesudason MR, Mukha RP, Vyas FL, Govil S, Muthusami JC. Management of adult choledochal cyst- a 15 year experience. HPB 2006; 8: 299-305.

16. Yamaguchi M. Congenital choledochal cyst. Analysis of 1,433 patients in the Japanese literature. Am J Surg. 1980,140(5):653-657.

17. Komi N, Tamura T, Miyoshi Y, Kunitomo K, Udaka H, Takehara H. Nationwide survey of cases of choledochal cyst. Analysis of coexistent anomalies, complications and surgical treatment in 645 cases. SurgGastroenterol. 1984; 3(2): 69-73.

18. Song HK, Kim MH, Myung SJ, Lee SK, Kim HJ, Yoo KS et al.Choledochal cyst associated with anomalous union of pancreaticobiliary duct (AUPBD) has a more grave clinical course than choledochal cyst alone. Korean J Intern Med. 1999; 14(2): 1-8.

19. Liu CL, Fan ST, Lo CM, Lam CM, Poon RT, Wong J. Choledochal cysts in adults. Arch Surg. 2002; 137(4): 465468.

20. Zheng LX, Jia HB, Wu DQ, Shang H, Zhong XY, Wang QS et al. Experience of congenital choledochal cyst in adults: treatment, surgical procedures and clinical outcome in the Second Affiliated Hospital of Harbin Medical University. J Korean Med Sci 2004; 19(6): 842-847. 
21. Liu YB, Wang JW, Devkota KR, JiZL, Li JT, Wang XA et al. Congenital choledochal cysts in adults: twenty-fiveyear experience. Chin Med J (Engl). 2007; 120(16): 14041407.

22. Huang CS, Huang CC, Chen DF. Choledochal cysts: differences between pediatric and adult patients. J Gastrointest Surg. 2010;14(7): 1105-1110.

23. Lee SE, Jang JY, Lee YJ, Choi DW, Lee WJ, Cho BH et al. Korean Pancreas Surgery Club. Choledochal cyst and associated malignant tumors in adults: a multicenter survey in South Korea. Arch Surg. 2011; 146(10):1178-1184.

24. Chaudhary A, Dhar P, Sachdev A, Kumar N, Vij JC, Sarin SK et al. Choledochal cysts - differences in children and adults. Br J Surg. 1996; 83(2): 186-188.

25. Palanivelu C, Rangarajan M, Parthasarathi R, Amar V, Senthilnathan P. Laparoscopic management of choledochal cysts: technique and outcomes - a retrospective study of 35 patients from a tertiary center. J Am Coll Surg. 2008; 207(6): 839-846.

26. Dhupar R, Gulack B, Geller DA, Marsh JW, Gamblin TC. The changing presentation of choledochal cyst disease: an incidental diagnosis. HPB Surg. 2009:103739.

27. Saluja SS, Nayeem M, Sharma BC, Bora G, Mishra PK . Management of choledochal cysts and their complications. Am Surg. 2012; 78 (3):284-290.

28. Dandpat SK, Prajapati R, Khajanchi M. Retrospective study of choledochal cyst: Clinical presentation, diagnosis and treatment. Int J Sc Res. 2014;3(11):352-380.

29. Patil V, KanetkarV, Talpallikar MC. Hepaticoduodenostomy for biliary reconstruction after surgical resection of choledochal cyst: a 25-year experience. Indian J Surg. 2015;77(Suppl 2):240-244.

30. Davenport M, Basu R. Under pressure: Choledochal malformation manometry. J Pediatr Surg. 2005; 40: 315331.

31. Elton E, Hanson BL, Biber BP, Howell DA. Dilated common channel syndrome: endoscopic diagnosis, treatment, and relationship to choledochocele formation. Gastroinest Endosc. 1998; 47:6471-6478.

32. Craig AG, Chen LD, Saccone GT, Chen J, Padbury RT, Toouli J. Sphincter of Oddi dysfunction associated with choledochal cyst. J GastroenterolHepatol. 2001; 16:230-
234.

33. Todani T, Watanabe Y, Narusue M, Tabuchi K, Okajima K. Congenital bile duct cysts: classification, operative procedures and review of thirty-seven cases including cancer arising from choledochal cyst. Am J Surg 1977;134: 263-269.

34. Miyano G, Yamataka A, Shimotakahara A. Cholecystectomy alone is inadequate for treatment of form fruste choledochal cyst: evidence from a rare but important case. PediatrSurg Int. 2005; 21:61-63.

35. Iwasaki Y, Shimoda M, Furihata T, Rokkaku K, Sakuma A, Ichikawa $\mathrm{K}$ et al. Biliary papillomatosis arising in a congenital choledochal cyst: report of a case. Surg Today. 2002; 32: 1019-1022.

36. Jeong IH, Jung YS, Kim H. Amylase level in extrahepatic bile duct in adult patients with choledochal cyst plus anomalous pancreaticobiliary ductal union. World J Gastroenterol. 2005; 11:1965-1970.

37. Sastry AV, Abbadessa B, Wayne MG, Steele JG, Cooperman AM. What is the incidence of biliary carcinoma in choledochal cysts, when do they develop, and how should it affect management? World J Surg. 2015;39 (2): 487-492.

38. He XD, Wang L, Liu W, Liu Q, Qu Q, Li BL et al. The risk of carcinogenesis in congenital choledochal cyst patients: an analysis of 214 cases. Ann Hepatol. 2014;13(6): 819826.

39. Shukla HS. Consensus document for management of gallbladder cancer [Internet]. ICMR 2014. [cited 31.1.2017]. Available from: http:// www.icmr.nic.in/ guide/cancer/Gall\%20Bladder/GALLBLADDER $\% 20$ CANCER.pdf

40. Lipsett PA, Pitt HA, Colombani PM, Boitnott JK, Cameron JL. Choledochal cyst. A changing pattern of presentation. Ann Surg. 1994; 220(5): 644-652.

41. Gadelhak N, Shehta A, Hamed H. Diagnosis and management of choledochal cyst: 20 years of single center experience. World J Gastroenterol. 2014; 20(22): 70617066.

42. Shen HJ, Xu M, Zhu HY, Yang C, Li F, Li KW et al. Laparoscopic versus open surgery in children with choledochal cysts: a meta-analysis. PediatrSurg Int. 2015; 31(6):529-534. 